\title{
Chronic Post-Exercise Lactate Administration with Endurance Training Increases Glycogen Concentration and Monocarboxylate Transporter 1 Protein in Mouse White Muscle
}

\author{
Daisuke HoshInO, Tatsuya HanAWA, Yumiko TAKAHASHI, \\ Hiroyuki MASUDA, Mai KATO and Hideo HATTA* \\ Department of Sports Sciences, Graduate School of Arts and Sciences, The University of Tokyo, \\ Tokyo 153-8902, Japan \\ (Received March 31, 2014)
}

\begin{abstract}
Summary Lactate is oxidized as an energy fuel during exercise, and it also plays a key role in the regulation of glycogen synthesis in the muscles and liver after exercise. Previous studies have suggested that lactate is converted to glycogen and stimulates glycogen synthesis. However, it remains unclear whether chronic post-exercise lactate administration can increase glycogen storage in skeletal muscle. We examined whether $3 \mathrm{wk}$ of chronic post-exercise lactate administration with training can increase muscle glycogen storage and whether such changes are associated with monocarboxylate transporter 1 (MCT1) protein expression in mice. Mice were assigned to receive saline with training (SA+T group; $n=6$ ) or lactate with training (LA+T group; $n=6$ ). All mice performed 40 min of treadmill running at $25 \mathrm{~m} / \mathrm{min}$, following which they received saline or lactate $(2.5 \mathrm{mg} / \mathrm{g}$ body weight), $6 \mathrm{~d} / \mathrm{wk}$ for $3 \mathrm{wk}$. After $3 \mathrm{wk}$, glycogen concentration at rest was higher in the white tibialis anterior (TA; $p<0.05,+34 \%$ ), but not in the red TA, in the LA+T group. Protein expression of MCT1, the primary lactate transporter, was increased with chronic post-exercise lactate administration in the white TA $(p<0.05,+32 \%)$, but not in the red TA. MCT1 protein expression was significantly correlated with muscle glycogen concentration in the red and white TA in both groups $(p<0.05, r=0.969)$. These results suggest that chronic lactate administration after exercise increases MCT1 protein expression, which can be involved in the regulation of the observed increase in muscle glycogen storage after exercise training.
\end{abstract}

Key Words skeletal muscle, glycogen, lactate supplementation, monocarboxylate transporter 1

Muscle glycogen storage at rest is a critical factor for maintaining physical performance during endurance exercise (1). Therefore, it is important to understand the mechanism underlying increased muscle glycogen storage at rest.

Lactate plays a key role in the regulation of glycogen synthesis in the muscles and liver at rest and after exercise. Classically, lactate was believed to be a precursor to hepatic gluconeogenesis only (Cori cycle), being converted to glucose that is directly transformed to glycogen in the liver and muscles. However, it was found that glycogen conversion from glucose also occurs through an indirect pathway via 3-carbon intermediates (e.g., lactate and amino acids) (2). Although skeletal muscle had not been considered to be a gluconeogenic organ, studies have demonstrated that muscles have the capacity to synthesize glycogen from lactate (3-6). To synthesize glycogen from lactate, lactate must be changed to pyruvate and then phosphoenolpyruvate (PEP). There are two potential pathways for the conversion of pyruvate into PEP. One is the pathway by which pyruvate is directly converted into PEP. This pathway of reverse

\footnotetext{
*To whom correspondence should be addressed.
}

E-mail: hatta@idaten.c.u-tokyo.ac.jp flux through pyruvate kinase is supported by previous studies $(7,8)$. The other is the pathway by which lactate is converted into oxaloacetate by pyruvate carboxylase and then oxaloacetate is converted into PEP by PEP carboxylase (PEPCK). Pyruvate carboxylase and PEPCK do exist in skeletal muscle though their activities are considered to be very low $(9,10)$. After that, glycogen is synthesized from glucose-6-phosphate (G6P) converted via the general gluconeogenesis pathway. In fact, recovery from glycogen depletion in rat muscle after exercise was accelerated with lactate infusion $(4,5,11)$. Although these results showed that lactate administration caused an acute increase in glycogen synthesis, it remains unknown whether chronic lactate supplementation accompanied with exercise can increase muscle and liver glycogen concentrations.

Lactate is primarily an energy fuel that is oxidized during exercise (12). Therefore, if lactate were supplemented before or during exercise, it would be oxidized for energy demands. In contrast, if supplemented after exercise, the rate of substrate oxidation decreases as the rate of glycogen resynthesis increases in skeletal muscle; therefore, lactate can be converted to glycogen, thereby stimulating glycogen synthesis after exercise. Indeed, Pagano et al. reported that maintaining blood lactate 
concentrations by lactate perfusion activated glycogen synthase activity in hind limb muscles (13). Therefore, it is possible that maintaining high blood lactate concentrations by post-exercise lactate supplementation can effectively increase muscle glycogen concentration. However, it is unknown if chronic post-exercise lactate supplementation with training can increase muscle glycogen storage.

Glucose transporter 4 (GLUT4) protein expression is one of the main regulators of muscle glycogen storage at rest (14) because glucose uptake into muscle is a limiting step (15). Despite the fact that lactate is also a source for glycogen, it remains unknown whether lactate transporter [monocarboxylate transporter (MCT)] protein expression affects glycogen replenishment in skeletal muscle. MCT facilitates lactate transport across the plasma membrane. Endurance exercise training increases MCT1 expression, which facilitates lactate uptake into muscle cells (16). Endurance training also increases muscle glycogen concentration, but it remains unknown whether increases in MCT1 protein expression are associated with glycogen concentration after training.

We hypothesized that chronic post-exercise lactate administration with training increases muscle glycogen concentration at rest compared with the same training without lactate administration. Furthermore, we expected that these changes in muscle glycogen would be associated with changes in MCT1 protein expression. Therefore, we examined whether post-exercise lactate administration with $3 \mathrm{wk}$ of training increased glycogen storage and MCT1 protein expression. We also examined other transporter proteins such as GLUT4 and fatty acid translocase (FAT)/CD36, which is a major fatty acid transporter, because high lactate concentrations may affect the expression of other transporter proteins (17).

\section{MATERIALS AND METHODS}

Animals. Male ICR mice ( 7 wk of age) were used in this study. The mice were housed in a climate-controlled room with a 12:12 h light-dark cycle. The animals were provided with standard chow and water ad libitum during the experimental period. All experimental treatments were approved by The University of Tokyo Committee on Animal Care.

Experimental design.

Acute lactate administration after a bout of exercise. Mice were assigned to a saline $(n=6)$ or a lactate administration group $(n=6)$. All mice performed a bout of exercise that was $60 \mathrm{~min}$ of treadmill running at $20 \mathrm{~m} /$ min. Immediately after the exercise, saline (same volume of lactate administration) or sodium lactate $(2.5 \mathrm{mg} / \mathrm{g}$ body weight) was orally administered to the respective groups. To check the effects of acute lactate administration after exercise, we measured lactate concentration for $120 \mathrm{~min}$ after exercise using a lactate meter (Lactate Pro; Arkray, Kyoto, Japan).

Chronic post-exercise lactate administration. Mice were assigned to one of two groups: saline administration with training $(\mathrm{SA}+\mathrm{T}, n=6)$ or lactate administra- tion with training $(\mathrm{LA}+\mathrm{T}, n=6)$. All mice performed $40 \mathrm{~min}$ of treadmill running at $25 \mathrm{~m} / \mathrm{min}, 6 \mathrm{~d}$ per week for $3 \mathrm{wk}$. All training sessions were performed between 9:00 a.m. and 12:00 noon. Immediately after each training bout, saline or sodium lactate $(2.5 \mathrm{mg} / \mathrm{g}$ body weight) was orally administered to the respective groups. The amount of food intake was measured daily during the 3-wk observation period. Tissues were harvested $48 \mathrm{~h}$ after the last training bout. The tissues were rapidly frozen in liquid nitrogen and stored at $-80^{\circ} \mathrm{C}$ until further analysis.

Muscle and liver glycogen concentrations. Muscle and liver glycogen concentrations were measured using the phenol-sulfuric acid method (18). Briefly, $300 \mu \mathrm{L}$ of $30 \% \mathrm{KOH}$ saturated with $\mathrm{Na}_{2} \mathrm{SO}_{4}$ was added to the muscle samples to dissolve the muscle completely. The homogeneous solutions were mixed with $360 \mu \mathrm{L}$ of $95 \%$ ethanol and placed on ice for $30 \mathrm{~min}$. The solutions were centrifuged at $840 \times g$ for $30 \mathrm{~min}$, and the supernatant was removed. The pellet (glycogen precipitate) was resuspended in $600 \mu \mathrm{L}$ of distilled water. Then, $200 \mu \mathrm{L}$ of the sample was combined with $100 \mu \mathrm{L}$ of phenol and 96-98\% $\mathrm{H}_{2} \mathrm{SO}_{4}$ and incubated for $10 \mathrm{~min}$ before reading the absorbance on a spectrometer at $490 \mathrm{~nm}$.

Protein isolation and Western blotting. Red and white tibialis anterior (TA) muscle samples were homogenized as previously described $(19,20)$ using lysis buffer (1\% Triton X-100, $50 \mathrm{~mm}$ Tris-HCl, $1 \mathrm{~mm}$ EDTA, $1 \mathrm{~mm}$ EGTA, $50 \mathrm{~mm}$ sodium fluoride, $10 \mathrm{~mm}$ sodium beta-glycerol phosphate, $5 \mathrm{~mm}$ sodium pyrophosphate, and $2 \mathrm{mM}$ dithiothreitol, $\mathrm{pH} 7.5)$ containing $10 \mu \mathrm{g} / \mathrm{mL}$ of pepstatin A, aprotinin, and leupeptin; $1 \mathrm{~mm}$ of $\mathrm{Na}$ orthovanadate, and $0.177 \mathrm{mg} / \mathrm{mL}$ of phenylmethylsulfonyl fluoride. Protein concentrations were measured by the Bradford method. Ten micrograms of whole-muscle protein was loaded in each lane. Whole-muscle proteins were separated using standard sodium dodecyl sulfate polyacrylamide gel electrophoresis (SDS-PAGE) procedures $(7.5 \%$ to $12 \%$ polyacrylamide gels $)$ and transferred to a polyvinylidene difluoride (PVDF) membrane. Membranes were blocked with $7.5 \%$ bovine serum albumin for $1 \mathrm{~h}$ and incubated overnight with antibodies specific for monocarboxylate transporter 1 (MCT1; Qiagen, Tokyo, Japan), glucose transporter 4 (GLUT4; Millipore, Temecula, CA), and fatty acid translocase/CD36 (FAT/ CD36; Abcam, Cambridge, MA) at $4^{\circ} \mathrm{C}$. Membranes were then incubated for $1 \mathrm{~h}$ at room temperature with secondary antibodies. The blots were quantified using a scanner (Chemidoc ${ }^{\mathrm{TM}}$; Bio-Rad, Hercules, CA) with appropriate software (Quantity One ${ }^{\circledR}$ 1-D Analysis Software; Bio-Rad). For Western blots, equal protein quantities were loaded and verified using glyceraldehyde 3-phosphate dehydrogenase (GAPDH; Abcam) protein content. MCT1, GLUT4 and FAT/CD36 protein expressions were normalized by GAPDH protein content.

Statistical analysis. All data are presented as means\pm standard errors. Statistical significance was determined using an unpaired, two-tailed, Student's t-test. Two-way repeated-measures analysis of variance 
(ANOVA) was used to analyze differences in blood lactate concentration (time $\times$ groups) and body weight (days $\times$ groups). When appropriate, post-hoc comparisons were performed using the Tukey's multiple comparisons test. Statistical significance was defined as $p<0.05$.

\section{RESULTS}

First, we orally administered lactate $(2.5 \mathrm{mg} / \mathrm{g}$ body weight) in mice after a single bout of exercise and then measured blood lactate concentrations for $120 \mathrm{~min}$. We confirmed that post-exercise lactate administration elevated blood lactate concentrations for $120 \mathrm{~min}$ after exercise $(p<0.05$, Fig. 1$)$. We next examined the effects of chronic post-exercise lactate administration with $3 \mathrm{wk}$ of training on glycogen stores and substrate transporters. To examine the effects of 3-wk chronic lactate administration on basal condition, we measured body weight, epididymal fat weight and daily food intake in each mouse. Body weights were lower in the $\mathrm{LA}+\mathrm{T}$ group than in the SA+T group on days $20-22(p<0.05$, Fig. 2A). Epididymal fat weight per gram of body weight tended to be lower in the LA+T group than in the $\mathrm{SA}+\mathrm{T}$ group after 3 wk $(-17 \%, p=0.07$, Fig. $2 \mathrm{~B})$. The amount of daily food intake was not significantly different between the two groups during the training period (Fig. 2C). We next examined the effects of lactate administration on TA and liver glycogen concentrations. Glycogen concentration in the white TA was higher in the LA+T group than in the $\mathrm{SA}+\mathrm{T}$ group $(+34 \%, p<0.05$, Fig. $3 \mathrm{~A})$; however, there was no difference in red TA glycogen concentration between groups (Fig. 3A). Liver glycogen was higher in the LA $+\mathrm{T}$ group than in the $\mathrm{SA}+\mathrm{T}$ group $(+61 \%, p=0.05$, Fig. 3B). To examine the effects of lactate administration on substrate transporters, we determined the specific transporter protein expression in red and white TA. MCT1 protein expression increased with lactate administration in the white TA $(+32 \%$, $p<0.05$ ), but not in the red TA (Fig. 4A). GLUT4, FAT/ CD36, and GAPDH protein levels were not altered in the red or white TA following chronic lactate administration

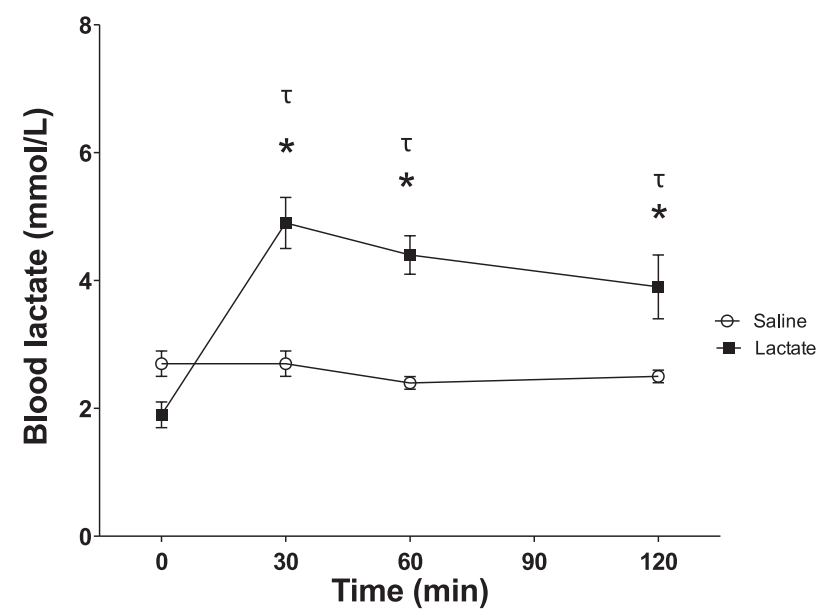

Fig. 1. Changes in blood lactate concentration with lactate $(2.5 \mathrm{mg} / \mathrm{g}$ body weight; $O$ ) or saline (same volume; 口) administration after $60 \mathrm{~min}$ of treadmill running at $20 \mathrm{~m} / \mathrm{min}$. Values are expressed as means \pm SE; $n=6$ animals for each group. ${ }^{*} p<0.05$ versus saline administration at the same time points. ${ }^{\top} p<0.05$ versus time 0 in the lactate administration group.
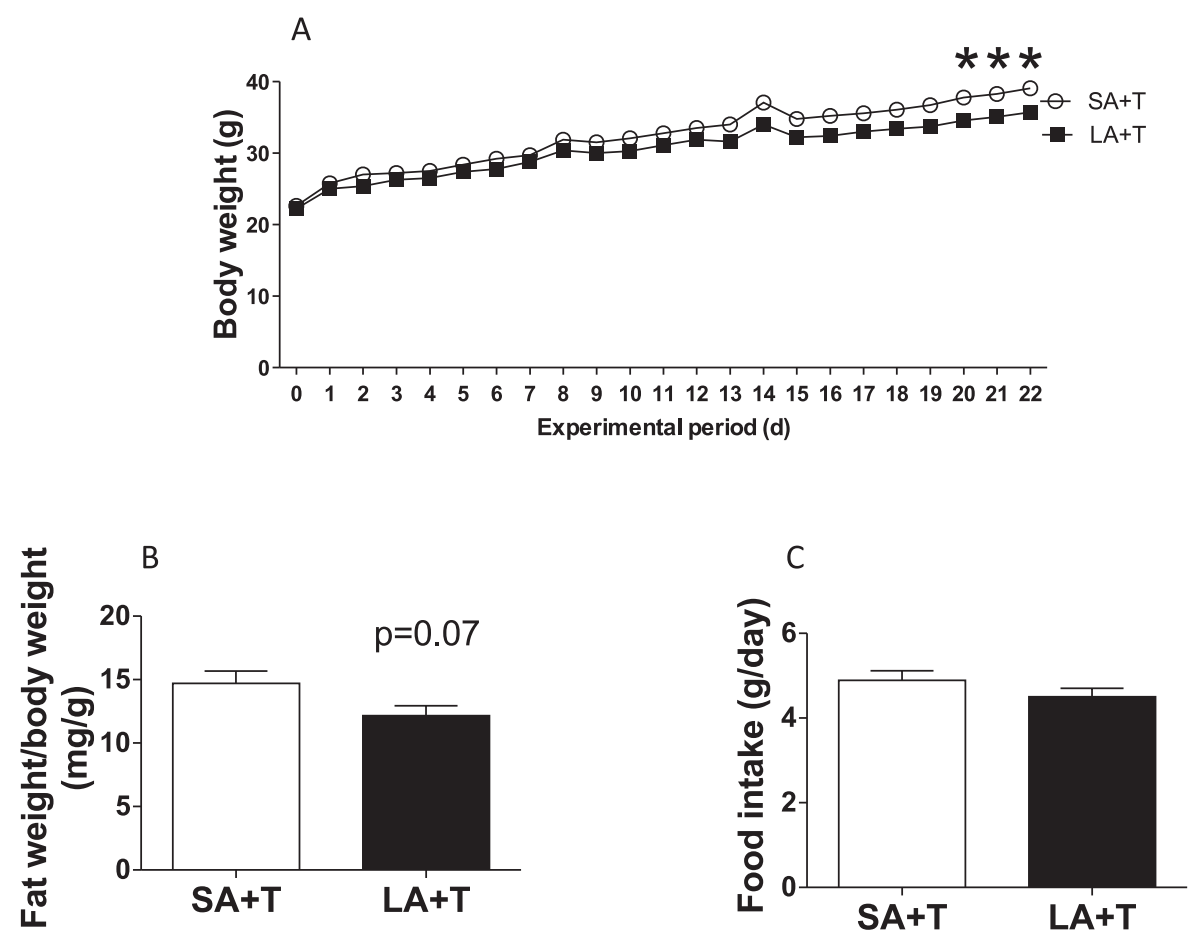

Fig. 2. Changes in body weights during the 3 -wk training period with saline $(O, S A+T)$ or lactate administration ( $\square$ LA +T) (A). Effects of chronic lactate administration on epididymal fat weight relative to body weight (B) and food intake per day $(C)$. Values are expressed as means \pm SE; $n=6$ animals for each group. ${ }^{*} p<0.05$, SA + T versus LA + T group. 

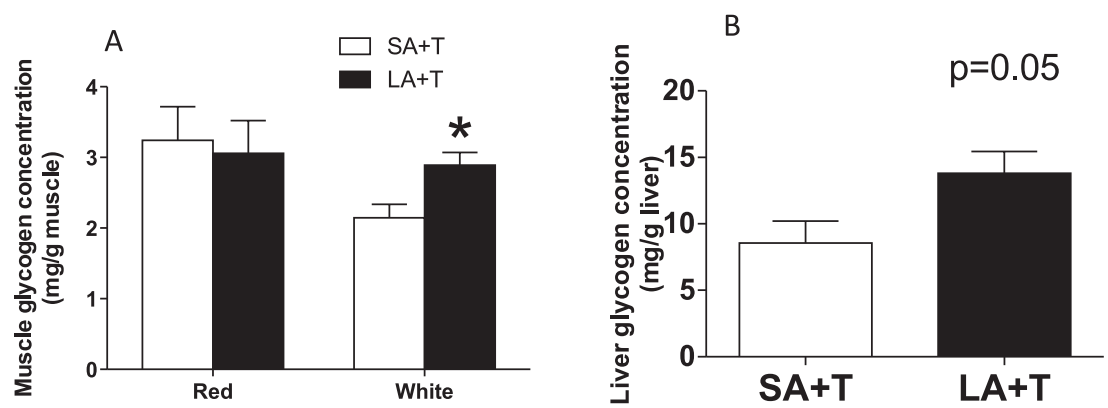

Fig. 3. Glycogen concentrations in the red and white TA (A) and liver (B) after 3 wk of saline (SA+T) or lactate (LA+T) administration with training. Values are expressed as means \pm SE; $n=6$ animals for each group. ${ }^{*} p<0.05, \mathrm{SA}+\mathrm{T}$ versus $\mathrm{LA}+\mathrm{T}$ group.
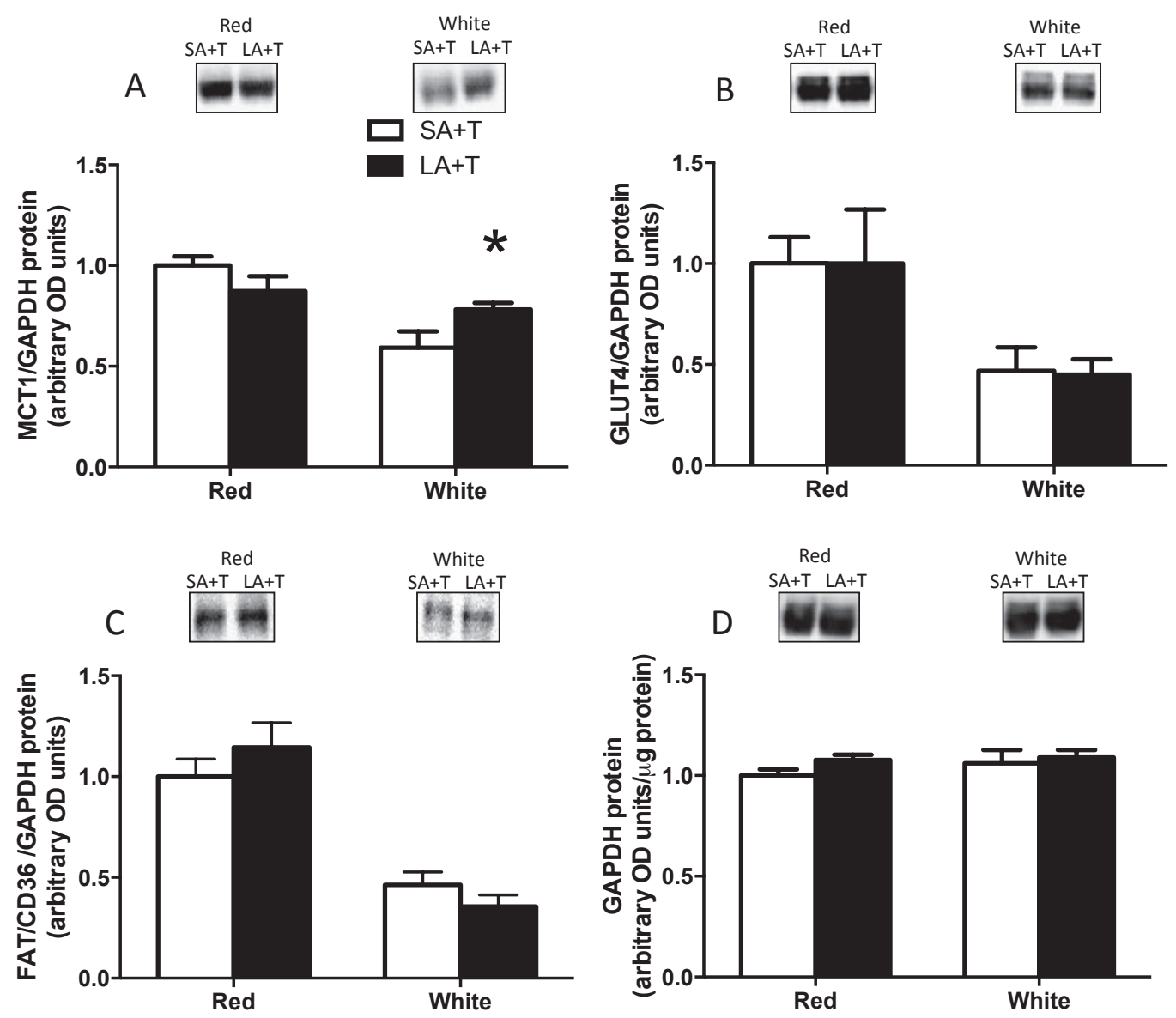

Fig. 4. Monocarboxylate transporter 1 (MCT1) (A), glucose transporter 4 (GLUT4) (B), fatty acid translocase/CD36 (FAT/ CD36) (C), and GAPDH (D) protein levels in the red and white TA after $3 \mathrm{wk}$ of saline (SA+T) or lactate administration $(\mathrm{LA}+\mathrm{T})$ with training. Representative bands are presented on the top of each figure. Values are expressed as means \pm SE; $n=6$ animals for each group. OD, optical density. ${ }^{*} p<0.05, \mathrm{SA}+\mathrm{T}$ versus LA $+\mathrm{T}$ group.

(Figs. 4B, 4C, 4D). MCT1 protein expression was significantly correlated with muscle glycogen concentration in the red and white TA in each group $(p<0.05, r=0.969$, Fig. 5).

\section{DISCUSSION}

We examined the effects of chronic post-exercise lactate administration on glycogen storage and substrate transporter protein expression. Three weeks of chronic post-exercise lactate administration with exercise train- ing increased glycogen concentration and MCT1 protein expression in the white TA compared with training alone. These results indicate that the increased glycogen storage induced by chronic post-exercise lactate supplementation with exercise training is likely to be mediated partly by an increase in MCT1 protein expression.

Three weeks of chronic post-exercise lactate administration with training increased the glycogen concentration in white muscle and liver, but not in red muscle. These results suggest that post-exercise lactate admin- 


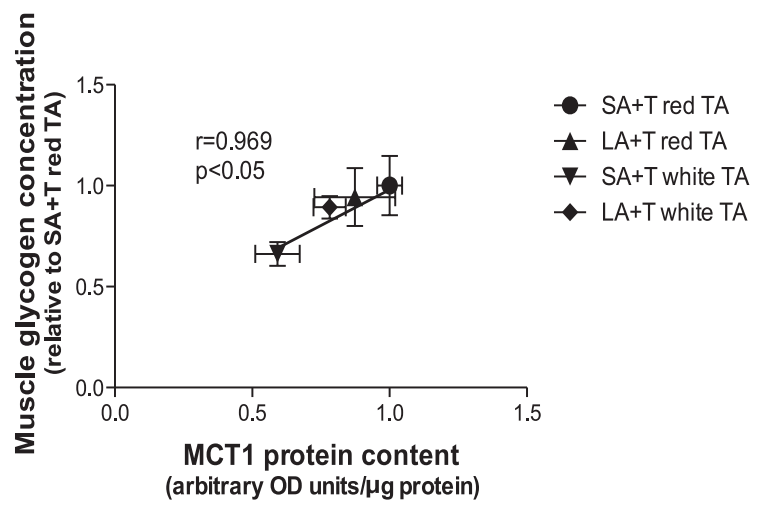

Fig. 5. Relationship between MCT1 protein contents and muscle glycogen concentrations in the red and white TA of each group. Significant correlation was found between MCT1 protein contents and glycogen concentrations. Values are expressed as means \pm SE; $n=6$ animals for each group. OD, optical density.

istration is a useful method to increase glycogen concentration in white muscle and liver. Consistent with the results of our study, previous studies suggest that gluconeogenesis from 3-carbon intermediates (e.g., lactate and amino acids), as well as glucose, also contributes to muscle glycogen synthesis after exercise (3, $4,11)$. Other studies have reported that exogenous lactate is converted to muscle glycogen via gluconeogenesis in perfused rats $(4,5,11)$ and that the conversion is greater in white muscle $(3,4)$. McLane and Holloszy reported that $8.5 \mathrm{~mm}$ of glucose with $12 \mathrm{~mm}$ of lactate perfusion increased glycogen concentration in white muscle (plantaris) compared with only lactate infusion (4). Meanwhile, the liver has greater capacity for indirect synthesis of glycogen from glucose via 3-carbon intermediates $(2,21)$. Zhang and Radziuk found that glucose with lactate infusion into the liver increased hepatic glycogen synthesis compared with the condition of infused glucose without lactate (21). In our study, the increased white TA and liver glycogen concentrations subsequent to lactate administration can be explained by cumulative stimulation of glycogen synthesis after exercise during the 3-wk training period. Post-exercise intake of carbohydrates accelerates muscle glycogen recovery (22), and GLUT4 protein expression and glucose uptake are limiting factors for glycogen recovery after training (14, 15). However, the present study suggests that gluconeogenesis from lactate as well as glucose can stimulate glycogen synthesis after an exercise bout.

One of the potential reasons why glycogen increases in white TA and liver but not in red TA is considered to be that the extent of depletion in glycogen by exercise is smaller in red TA than the other tissues because red muscle has high mitochondrial content and a low glycogenolysis rate during exercise. In contrast to red TA, glycogen concentration in white TA is regarded as having decreased largely after exercise. Muscle glycogen reduction itself by exercise is associated with muscle metabolic adaptation after exercise training (23). For example, mitochondrial adaptation occurred in white
TA (superficial and middle region of TA in the study) but not in red TA (deep region of TA) after $4 \mathrm{wk}$ of wheel running exercise (24). These results including the present study suggest that, in red muscles, glycogen degradation during endurance exercise such as wheel and treadmill running at low speed was not sufficient to induce muscle metabolic adaptation, namely increases in mitochondrial content and glycogen concentration. In liver, glycogen also decreased in rodents at the early phase of exercise for the maintenance of the concentration of plasma blood glucose (25). Indeed, we confirmed the reduction in glycogen concentration in liver and red TA after $60 \mathrm{~min}$ of treadmill running at $20 \mathrm{~m} /$ min under overnight fasted condition in the preliminary experiment. Previous studies suggest that sufficient glycogen depletion and high plasma lactate concentration are important to increase the contribution of lactate for glycogen synthesis $(3,6)$. Collectively, it is considered that the increase in glycogen concentrations in white TA and liver is associated with an elevation in the contribution of lactate for glyconeogenesis in these tissues.

Lactate is not only a precursor to gluconeogenesis in muscles and liver but also an oxidizable substrate in skeletal muscle, even after exercise (26). Red muscle has more mitochondrial content than white muscle, indicating a higher oxidative capacity of lactate (27). The observation that glycogen stores were increased only in white muscle is justified because red muscle has higher oxidative capacity (27) while white muscle has a higher capacity for gluconeogenesis from 3-carbon intermediates $(3,4)$. Therefore, in red muscle, much of the lactate may be oxidized, rather than being converted to glucose and glycogen, after exercise.

To date, supplementations of glucose and/or a highcarbohydrate diet have been used to increase muscle glycogen concentration (28). The result of this study proposed that lactate administration is also an ergogenic aid for glycogen loading as well as glucose supplementation. However, there is no study comparing the effects of glucose or lactate administration on training adaptation. We need to clarify this issue in future studies. On the other hand, daily high-carbohydrate intake induced the increase of glucose availability and exogenous carbohydrate oxidation rate during exercise (29) though changes in GLUT4 protein expression and some metabolic adaptations did not occur $(29,30)$. In the present study, the close relationship between MCT1 protein expressions and glycogen concentrations suggests an increase in availability of lactate for glycogen synthesis in skeletal muscles. Thus, lactate administration may lead to improved lactate availability and oxidative capacity in skeletal muscles with a concomitant increase in muscle glycogen concentration at rest.

Concurrent to the increase in glycogen concentration, MCT1 protein expression also increased in white muscle after chronic lactate administration with training. Our results demonstrate that MCT1 protein expression was significantly correlated with muscle glycogen concentration in the red and white TA in each group. This close relationship suggests that MCT1, which facili- 
tates lactate uptake by muscle cells, is also important for glycogen regulation. One potential explanation for this correlation is that lactate can be converted to glycogen directly in skeletal muscle (not via conversion to glucose in the liver). Another explanation is that lactate activates glycogen synthase (GS), which is a crucial factor in glycogen concentration at rest as well as resynthesis after exercise (31). Although we did not measure GS activity in this study, Pagano et al. demonstrated that lactate infusion increased hyperglycemia-induced glycogen resynthesis in rat hindlimb muscle, which was accomplished by the activation of GS activity (13). The study suggests that lactate can increase glycogen concentration at rest because of the elevation in GS activity. Taken together, it is likely that increases in MCT1 protein expression and lactate uptake are involved in the regulation of muscle glycogen concentration at rest after exercise training.

Mice supplemented with lactate after training exhibited higher MCT1 protein expression compared with those that underwent training with no lactate supplementation. MCT4 is also a major MCT for lactate metabolism. We did not measure the MCT4 lactate transporter because MCT4 plays a role in releasing lactate from muscle to other tissues, not uptake into muscle, and has a much higher $\mathrm{Km}$ value for lactate compared with MCT1 (32). Hashimoto et al. reported that lactate can be a signal to increase MCT1 and mitochondrial protein expression, but not MCT4 (33). In our study, post-exercise lactate administration increased the blood lactate concentration to approximately $5 \mathrm{mmol} / \mathrm{L}$ for $2 \mathrm{~h}$. We speculate that the higher lactate concentration is the result of the increased MCT1 protein expression. On the other hand, lactate administration did not change the expression of other substrate transporters; namely GLUT4 and FAT/CD36. Infusion of several energy substrates can change substrate transporter expression because of the selection of substrate utilization (17, 34). Lombardi et al. reported that hyperlactatemia for $24 \mathrm{~h}$ decreases GLUT4 mRNA and protein expression in muscle (17). These differing results can be associated with the concentration and/or duration of lactate infusion and administration. Taken together, these findings suggest that approximately $5 \mathrm{mmol} / \mathrm{L}$ of blood lactate concentration for $2 \mathrm{~h}$ can increase in MCT1 protein expression but the maintenance of higher blood lactate concentration for longer intervals would be required to affect the expression of other substrate transporters.

The results of an increase in MCT1 protein expression and a decrease in fat weight $(p=0.07)$ by chronic lactate administration were associated with exercise performance. MCT1 protein contents were positively correlated with the duration of incremental all-out exercise test (35). The LA + T group had lower body weights. This result was explained in part by lower fat weights in the $\mathrm{LA}+\mathrm{T}$ group than in the $\mathrm{SA}+\mathrm{T}$ group. Hashimoto et al. recently reported that lactate stimulation promoted lipolysis in 3T3-L1 adipocyte (36). Therefore, lactate administration may be a useful method to increase MCT1 protein expressions in skeletal muscles and the fat degradation rate in adipose tissues to improve exercise performance.

\section{CONCLUSIONS}

Three weeks of chronic post-exercise lactate administration increased glycogen concentration as well as MCT1 protein expression in the white TA. These results suggest that chronic post-exercise lactate administration increases muscle glycogen storage and that increased MCT1 may be critical for increases in glycogen concentrations after exercise training.

\section{Acknowledgments}

This study was partially supported by a grant (Grantin-Aid for Research Activity Start-up: 23800021) from Japan Society for the Promotion of Science (JSPS).

\section{REFERENCES}

1) Bergstrom J, Hermansen L, Hultman E, Saltin B. 1967. Diet, muscle glycogen and physical performance. Acta Physiol Scand 71: 140-150.

2) Newgard CB, Moore SV, Foster DW, McGarry JD. 1984. Efficient hepatic glycogen synthesis in refeeding rats requires continued carbon flow through the gluconeogenic pathway. J Biol Chem 259: 6958-6963.

3) Johnson JL, Bagby GJ. 1988. Gluconeogenic pathway in liver and muscle glycogen synthesis after exercise. J Appl Physiol 64: 1591-1599.

4) McLane JA, Holloszy JO. 1979. Glycogen synthesis from lactate in the three types of skeletal muscle. J Biol Chem 254: 6548-6553.

5) Stevenson RW, Mitchell DR, Hendrick GK, Rainey R, Cherrington AD, Frizzell RT. 1987. Lactate as substrate for glycogen resynthesis after exercise. J Appl Physiol 62: 2237-2240.

6) Shiota M, Golden S, Katz J. 1984. Lactate metabolism in the perfused rat hindlimb. Biochem J 222: 281-292.

7) Jin ES, Sherry AD, Malloy CR. 2009. Evidence for reverse flux through pyruvate kinase in skeletal muscle. Am J Physiol Endocrinol Metab 296: E748-E757.

8) Dobson GP, Hitchins S, Teague WE Jr. 2002. Thermodynamics of the pyruvate kinase reaction and the reversal of glycolysis in heart and skeletal muscle. J Biol Chem 277: 27176-27182.

9) Minet AD, Gaster M. 2010. Pyruvate carboxylase is expressed in human skeletal muscle. Biochem Biophys Res Commun 402: 196-197.

10) Duff DA, Snell K. 1982. Limitations of commonly used spectrophotometric assay methods for phosphoenolpyruvate carboxykinase activity in crude extracts of muscle. Biochem J 206: 147-152.

11) Ryan C, Radziuk J. 1995. Distinguishable substrate pools for muscle glyconeogenesis in lactate-supplemented recovery from exercise. Am J Physiol 269: E538-E550.

12) Mazzeo RS, Brooks GA, Schoeller DA, Budinger TF. 1986. Disposal of blood [1-13C]lactate in humans during rest and exercise. J Appl Physiol 60: 232-241.

13) Pagano C, Granzotto M, Giaccari A, Fabris R, Serra R, Lombardi AM, Federspil G, Vettor R. 1997. Lactate infusion to normal rats during hyperglycemia enhances in vivo muscle glycogen synthesis. Am J Physiol 273: R2072-R2079.

14) Nakatani A, Han DH, Hansen PA, Nolte LA, Host HH, Hickner RC, Holloszy JO. 1997. Effect of endurance exer- 
cise training on muscle glycogen supercompensation in rats. J Appl Physiol 82: 711-715.

15) Ren JM, Semenkovich CF, Gulve EA, Gao J, Holloszy JO. 1994. Exercise induces rapid increases in GLUT4 expression, glucose transport capacity, and insulinstimulated glycogen storage in muscle. J Biol Chem 269: 14396-14401.

16) Bonen A, Tonouchi M, Miskovic D, Heddle C, Heikkila JJ, Halestrap AP. 2000. Isoform-specific regulation of the lactate transporters MCT1 and MCT4 by contractile activity. Am J Physiol Endocrinol Metab 279: E1131-E1138.

17) Lombardi AM, Fabris R, Bassetto F, Serra R, Leturque A, Federspil G, Girard J, Vettor R. 1999. Hyperlactatemia reduces muscle glucose uptake and GLUT-4 mRNA while increasing (E1alpha)PDH gene expression in rat Am J Physiol 276: E922-E929.

18) Lo S, Russell JC, Taylor AW. 1970. Determination of glycogen in small tissue samples. J Appl Physiol 28: 234-236.

19) Hoshino D, Yoshida Y, Holloway GP, Lally J, Hatta H, Bonen A. 2012. Clenbuterol, a beta2-adrenergic agonist, reciprocally alters PGC-1 alpha and RIP140 and reduces fatty acid and pyruvate oxidation in rat skeletal muscle. Am J Physiol Regul Integr Comp Physiol 302: R373-R384.

20) Kitaoka Y, Machida M, Takemasa T, Hatta H. 2011. Expression of monocarboxylate transporter (MCT) 1 and MCT4 in overloaded mice plantaris muscle. J Physiol Sci 61: 467-472.

21) Zhang Z, Radziuk J. 1994. Coordinated regulation of hepatic glycogen formation in perfused rat liver by glucose and lactate. Am J Physiol 266: E583-E591.

22) Ivy JL, Katz AL, Cutler CL, Sherman WM, Coyle EF. 1988. Muscle glycogen synthesis after exercise: effect of time of carbohydrate ingestion. J Appl Physiol 64: 1480-1485.

23) Philp A, Hargreaves M, Baar K. 2012. More than a store: regulatory roles for glycogen in skeletal muscle adaptation to exercise. Am J Physiol Endocrinol Metab 302: E1343-E1351.

24) Ishihara A, Hirofuji C, Nakatani T, Itoh $\mathrm{K}$, Itoh $\mathrm{M}$, Katsuta S. 2002. Effects of running exercise with increasing loads on tibialis anterior muscle fibres in mice. Exp Physiol 87: 113-116.

25) Armstrong RB, Saubert IV CW, Sembrowich WL, Shepherd RE, Gollnick PD. 1974. Glycogen depletion in rat skeletal muscle fibers at different intensities and durations of exercise. Pflugers Arch 352: 243-256.

26) Hatta H, Atomi Y, Yamamoto Y, Shinohara S, Yamada S. 1988. Oxidation of lactate in rats after short-term strenuous exercise. Int J Sports Med 9: 429-432.

27) Brooks GA. 2000. Intra- and extra-cellular lactate shuttles. Med Sci Sports Exerc 32: 790-799.

28) Burke LM. 2010. Fueling strategies to optimize performance: training high or training low? Scand J Med Sci Sports 20: $48-58$.

29) Cox GR, Clark SA, Cox AJ, Halson SL, Hargreaves M, Hawley JA, Jeacocke N, Snow RJ, Yeo WK, Burke LM. 2010. Daily training with high carbohydrate availability increases exogenous carbohydrate oxidation during endurance cycling. J Appl Physiol 109: 126-134.

30) De Bock K, Derave W, Eijnde BO, Hesselink MK, Koninckx E, Rose AJ, Schrauwen P, Bonen A, Richter EA, Hespel P. 2008. Effect of training in the fasted state on metabolic responses during exercise with carbohydrate intake. J Appl Physiol 104: 1045-1055.

31) Fogt DL, Pan S, Lee S, Ding Z, Scrimgeour A, Lawrence JC Jr, Ivy JL. 2004. Effect of glycogen synthase overexpression on insulin-stimulated muscle glucose uptake and storage. Am J Physiol Endocrinol Metab 286: E363-E369.

32) Dimmer KS, Friedrich B, Lang F, Deitmer JW, Broer S. 2000. The low-affinity monocarboxylate transporter MCT4 is adapted to the export of lactate in highly glycolytic cells. Biochem J 350: 219-227.

33) Hashimoto T, Hussien R, Oommen S, Gohil K, Brooks GA. 2007. Lactate sensitive transcription factor network in L6 cells: activation of MCT1 and mitochondrial biogenesis. FASEB J 21: 2602-2612.

34) Vettor R, Fabris R, Serra R, Lombardi AM, Tonello C, Granzotto M, Marzolo MO, Carruba MO, Ricquier D, Federspil G, Nisoli E. 2002. Changes in FAT/CD36, UCP2, UCP3 and GLUT4 gene expression during lipid infusion in rat skeletal and heart muscle. Int J Obes Relat Metab Disord 26: 838-847.

35) Kitaoka Y, Wakasugi Y, Hoshino D, Mukai K, Hiraga A, Hatta H. 2010. Effects of high-intensity training on monocarboxylate transporters in Thoroughbred horses. Comp Exer Physiol 6: 171-175.

36) Hashimoto T, Sato K, Iemitsu M. 2013. Exercise-inducible factors to activate lipolysis in adipocytes. J Appl Physiol 115: 260-267. 